Javier

Facco

\section{Universidad}

Nacional de

Rosario, Argentina

javierfacco@yahoo.com.ar

Recibido: 17.01 .18

Aceptado: 07.07.18

\title{
Apuntes sobre la aequitas en la tradición canónica medieval
}

\section{Notes about aequitas in the Medieval Canonical Tradition}

Resumen: La equidad surge en la Edad Media como concepto clave para intentar la unidad jurídica y del derecho en el contexto de una sociedad en la que la Iglesia impregna todo el ordenamiento humano desde el derecho canónico. El concepto dicho, que se muestra notablemente polivalente, se irá decantando con significados analógicos e irá permeando también el derecho "secular". Así, en la alta Edad Media, la aequitas - con justificada pretensión de ordenar la realidad en su conjunto - será principio inspirador del orden social al hacer posible conservar la paz y la concordia.

Palabras clave: Aequitas canonica; derecho canónico medieval; historia del derecho canónico.

\begin{abstract}
Equity arises in the Middle Ages as a key concept as an intend to achieve judicial and law unity. Equity appeared in a social context where the canon law influenced the whole the human code. The aforementioned concept, outstanding for its versatility, would start to be polished by analogical meanings, and it will also permeate the "secular" law. Furthermore, equity has the justified pretention of ordering society as a whole. In that way, aequitas will be the inspiring beginning of the social order as it will keep peace and concord.
\end{abstract}

Keywords: Aequitas canonica, Medieval canon law; canon law history.
El ius commune ha sido la elaboración jurídica más conspicua de la baja Edad Media (siglos XI-XV) y considerado el substractum jurídico general de Europa occidental (Margadant, 1986, p. 146). El mismo se forjó sobre la base del derecho romano justinianeo y del derecho canónico, sus dos componentes principales, gracias a la labor académica de civilistas y canonistas cuyo centro residió en las Universitates (a su vez, vinculadas al desarrollo de la civilización comunal).
En todo caso, como lo advierte Ennio Cortese, el ius commune es una expresión cargada de ambigüedades, entre otros factores, dado el carácter dual de este conjunto no exento de tensiones en la difícil tarea de compatibilizar sus dos ingredientes constitutivos, habida cuenta de la diversidad de origen (distintas fuentes y ordenamientos en los que abrevaba cada una de sus partes) y de los diferentes 
territorios a los que se aplicaba o se pretendía aplicar tal denominación (Cortese, 2013)․․

Al margen de esta necesaria advertencia en la reconstrucción histórica del concepto, en un plano puramente ideal y dogmático su configuración fundada en la relación entre leges romanas y cánones eclesiásticos responde a la analogía con el estrecho vínculo mantenido en la concepción cristiana entre cuerpo (derecho romano) y alma (derecho canónico). Bartolo de Saxoferrato, por ejemplo, sostenía que el primero le prestaba autoridad al derecho común, mientras que el segundo le confería santidad. Así como la vida humana en la concepción medieval solo era perfecta por la armonía entre cuerpo y espíritu, el utrumque ius (uno y otro derecho) era el reflejo normativo de la utrumque vitae (una y otra vida: terrenal y eterna).

Un dato cierto es que la expresión ius commune pone de resalto la dicotomía entre un plexo de normas generales (no ciertamente homogéneas), por un lado, y los derechos particulares/especiales/locales (de origen estatutario o consuetudinario), por el otro (Cortese, 2013, p. 823). La compleja dialéctica entre ambos se resolvía asignando una función supletoria al ius commune, conforme a la cual oficiaba de ordenamiento subsidiario de los iura propria (nótese la importancia del uso del plural en esta expresión), es decir, restando como depositario de reglas, conceptos, rationes y principios disponibles para la resolución de los casos cuando la ausencia de alguna norma especial o local lo aconsejaba.

De las diversas soluciones que ofrecían ambos derechos, los juristas medievales en muchas ocasiones prefirieron las canónicas, toda vez que el antiguo derecho justinianeo había devenido anacrónico en ciertas materias a la luz del sentir de la época. En efecto, el derecho canónico representaba un modelo más actual y adaptado, fruto del estudio de los canonistas de Bolonia. Cabe tener presente que este derecho canónico no se limitó a regular materias eclesiásticas, sino que, en virtud del poder indirecto que ejercían los papas en orden a la salvación de las almas, abordó además cuestiones temporales ${ }^{2}$.

Ahora bien, conviene primero trazar un sucinto diagnóstico del contexto cultural imperante en los primeros siglos de la Edad Media, que se caracterizó por el quiebre de la unidad política, la dispersión normativa y la consecuente superposición de ordenamientos jurídicos vigentes. La resultante de todo ello se concretó en una respuesta de la Iglesia que intervino en materias seculares con el fin de uniformar y clarificar el derecho aplicable e infundió a este efecto una sólida doctrina moral que debía ser observada por todos los fieles.

\footnotetext{
1 Nótese cómo este autor enseña que la concepción de matriz idealista propuesta por Francesco Calasso desde 1934 proyecta la imagen dogmática sobre el plano histórico y a partir de allí postula un sistema de ius commune universal destinado a imperar sobre todo el mundo cristiano desde los comienzos del segundo milenio. Añade Cortese que semejante trasposición podría ser adecuada para el Regnum Italiae que Calasso toma como modelo para su reconstrucción (en el territorio del centro-norte de la península itálica donde los dos cetros, real e imperial, estaban concentrados en la misma mano, y, por lo tanto, el corpus justinianeo podía transformarse en el nuevo derecho común cuando allí se aceptaba sin discusiones su vigencia). Empero, en otros ambientes (tales como las Galias, la península ibérica, Inglaterra e incluso en el Reino de Sicilia), en los cuales la legitimación ratione Imperii de las leges entraba en conflicto con la plena soberanía de esos reinos, la aplicación de estas en tanto ius commune no podía ser acogida tan fácilmente.

${ }^{2}$ La salvación de las almas era una preocupación central para el hombre medieval y ha tenido hondas repercusiones en todas las dimensiones de su existencia. Al respecto puede verse: Campitelli, A. (2007). Europeenses: Presupposti storici e genesi del diritto comune. Bari: Cacucci; Ascheri, M. (2007). II diritto dal Tardo Impero romano all'Alto Medioevo (extracto de M. Ascheri, Introduzione storica al diritto medievale). Turín: Giappichelli; y, para un cuadro sistemático y ampliamente documentado del periodo subexamine: Calasso, F. (1954). Medio Evo del Diritto, 1, Milán: Giuffrè. Hay un estudio específico del derecho italiano en Di Simone, M. R. (2007). Istituzioni e fonti normative in Italia dall'antico regime al fascismo. Turín: Giappichelli.
} 


\section{Fractura de la unidad político-jurídica y profusión de ordenamientos vigentes en la alta Edad Media}

En el curso de algo más de mil años, entre la caída del Imperio romano de Occidente (476 d.C.) y el primer desembarco de los conquistadores en América (1492 d.C.), no se conoce el desarrollo de ordenamientos jurídicos unitarios en Europa. Sin embargo, esta situación fue más acuciante durante la alta Edad Media (siglos V-X), cuando luego de las invasiones barbáricas se recibieron múltiples instituciones y leyes nacidas de exigencias disímiles (diversitas legum) (Gatto, 2003, p. 145).

Con la caída del Imperio romano de Occidente, Bizancio resta como la heredera de Roma (romanorum legum), tal como lo atestiguan el Codex Theodosianum (438-439 d.C.) y en el siglo sucesivo la compilación justinianea. En la península itálica, por ejemplo, la introducción de los códigos de Justiniano constituyó un problema sumamente complejo que no resulta fácil abordar en esta sede. Sin embargo, es posible fijar una fecha como verdadero terminus inicial de su vigencia en el territorio italiano: la Pragmatica Sanctio del 13 de agosto del año 554, cuando por expreso requerimiento del papa Vigilio (pro petitione Vigilii) la península (que había sido reconquistada durante un breve tiempo por los bizantinos con lo que se restauró la autoridad imperial) acoge en su versión más actual el derecho que anteriormente había tenido origen en Roma (Schipani, 2005, p. XV). Empero, será efímero este retorno del derecho romano en Italia, pues en el año 568 d.C. bajo la dominación de los longobardos comenzará un difícil y dramático episodio (Gatto, 2003, p. 146) ${ }^{3}$.

Así fue que los distintos dominadores introdujeron las fuentes de sus propios derechos. Tal es el caso de las denominadas leyes romano-barbáricas (lex romana Visigothorum y lex romana Burgundiorum), aunque diluidas por la presencia de algunos resabios del derecho romano del período precedente. Por su parte, Teodorico "el Grande" (493-526 d.C.) con su Edictum del año 503, a diferencia de la lex adoptada por los visigodos y borgoñeses, propone una lex derivada del ius edicendi que le fuera conferido por el emperador de Oriente, respecto de quien se reputa Magistratus ${ }^{4}$.

La ruptura jurídica se consumará definitivamente con el cuerpo de normas introducidas por los longobardos, cuando el rey Rotario (rex gentis Langobardorum) promulga el edicto conocido con su nombre el 22 de noviembre del año 643. Esta fue la más completa de las legislaciones barbáricas, donde se condensó una suma de leyes cuyo significado se encontraba ligado casi totalmente a la cultura y civilización germánica, más allá de que la obra haya sido el resultado de la labor de compiladores romanos y eclesiásticos 5 .

\footnotetext{
${ }^{3}$ En este sentido precisa con agudeza S. Schipani (2005, p. XV): "[F]atti storici e istituzionali diversi, e in primo luogo il regno dei Longobardi, con la sua capitale a Pavia, conquistata nel 572, rallentarono questo superamento in parte della penisola che risultò divisa, e ne resero la vicenda più articolata". Para profundizar sobre la influencia ejercida por el derecho bizantino en el territorio itálico remitimos a Brandileone (1929).

${ }^{4}$ A este respecto puntualiza Gatto (2003, p. 146) que fue bien diversa la finalidad perseguida por Teodorico, quien intentó fusionar la condición jurídica de romanos y bárbaros. Así, en el Proemio del EdictumTheodoriciregis subraya que barbari romanique debían observar por igual las normas del edicto. El mismo fue una excepción frente a las otras leyes romano-barbáricas, ya que se apartaba del principio de personalidad y consagraba el de territorialidad. Esto no era casual considerando que tenía por principal objeto regular problemas territoriales en los lugares donde convivían romanos y bárbaros.

${ }^{5}$ El edicto de Rotario fue la primera recolección escrita de leyes de los longobardos. Redactado en latín pero con muchas palabras lombardas (con inflexiones latinizadas), es un importante documento para el estudio de esta lengua. Según el principio de la personalidad de la ley, el edicto era solo aplicable a la población italiana de origen longobardo; la de origen romano seguía rigiéndose por el derecho codificado en el Digesto. En esencia, el edicto de Rotario buscaba recomponer las relaciones entre ciudadanos sustituyendo las venganzas privadas (faidas) por resarcimientos o compensaciones pecuniarias. Para mayor detalle véase A. Cavanna (1968); M. Tosi (1982) y, en especial, G. Astuti (1975).
} 
Un primer intento de restablecer la unidad política que se había fragmentado desde la caída de Roma, aunque de breve duración, se registra a partir de la fundación del Sacro Imperio Romano, cuando en la Navidad del 800 el pontífice León III coronó emperador al rey de los francos Carlo Magno. Desde este momento se otorgan una serie de Capitularia ${ }^{6}$ que se adicionaban a las leyes populares de ciertos reinos (Capitula legibus addenda) $)^{7}$ y a cuya observancia se encontraban obligados todos los súbditos del Imperio. El objetivo era asegurar la unidad política, sometiendo a todos los individuos que habitaban los territorios del Imperio a una organización administrativa uniforme ${ }^{8}$. El emperador encarnaba no solo las atribuciones propias del poder secular, sino que además se auto-titulaba el representante de Dios en la tierra y, por lo tanto, su competencia pretendía extenderse a materias espirituales, aunando así la suma de prerrogativas tanto en el campo civil como religioso.
Veamos, por ejemplo, el Capitula italicum que recoge los capitularia carolingios relativos al Reino itálico (Regnum italiae) (Cortese, 2000, p. 142). En él se evidencia la necesidad de contemporizar la ley en función de los territorios y los pueblos a los cuales resultaba aplicable, dado el contraste entre las numerosas leyes populares y el complejo unitario imperial ${ }^{9}$. En todo caso, la tensión entre la ansiada unidad política y el particularismo jurídico favoreció una compleja articulación de la cual brotarán los primeros gérmenes del ius commune en el tentativo de subvenir a las peculiares exigencias y aspiraciones de los diversos pueblos ${ }^{10}$. No obstante, los tiempos todavía no habían madurado lo suficiente y será recién cuando las estructuras eclesiásticas logren consolidarse e institucionalizarse que podrá hablarse de un orden jurídico más o menos unitario en el mundo medieval. Así, a inicios del segundo milenio de la era cristiana, a la par del florecimiento del derecho civil, comienza a darse un desarrollo orgánico del ordenamiento jurídico eclesiástico'11.

\footnotetext{
${ }^{6}$ Los soberanos carolingios tuvieron una relevante producción normativa, pese a las escasas exigencias de una vida simple como la de entonces. Sus normas eran designadas con el término capitularia, porque no aparecían aisladamente como preceptos singulares, sino bajo la forma de series más o menos extensas (y no siempre homogéneas) de breves capítulos. Con ello se habría operado un cambio radical en el lenguaje legislativo y así, la palabra lex quedó reservada para indicar los complejos normativos populares, desapareció el vocablo edictum y se atenuó gradualmente el uso de decretum o decretio, praeceptum o praeceptio (nombres provenientes de la Antigüedad romana) (Cortese, 2000, p. 128).

${ }^{7}$ Los capitularia fueron especificándose (en particular luego de la muerte de Carlo Magno en el año 814) en categorías diversificadas según su función. Los capitularia ecclesiastica contenían providencias relativas al clero, las iglesias y los monasterios (y se oponían a los capitularia mundana que se referían al mundo laico); los capitularia missorum establecían las instrucciones que debían observar los missidominici (funcionarios enviados a la periferia para representar al soberano en tareas de gobierno, jurisdicción y control); y los capitularia legibus addita o addenda tenían la importante finalidad de modificar y actualizar (rectius: adaptar a la voluntad del soberano) las leges populares ancestrales (fundadas en viejas costumbres y tradiciones de diversos grupos étnicos germanos) (Cortese, 2000, p. 127). Para ampliar sobre el punto, ver Ganshof (1958), con una tabla de los capitularia estudiados y un índice alfabético general; y Astuti (1958), la voz Capitolari.

${ }^{8}$ En términos generales, el intento unificador es puesto de relieve por Schipani (2005, pp. XV-XVI), cuando explica que la coronación como emperador de Carlo Magno: “... aveva posto in movimento una dinamica unificatrice di quell'agglomerato di popoli e istituzioni che si era venuto concentrando sotto il potere del sovrano franco, dinamica che apriva alla riflessione sulla prospettiva della lex communis, e quindi della lex Romana".

${ }^{9}$ En este sentido, Agobardo, siendo obispo de Lyon en el año 813, en una epístola dirigida a Ludovico Pio (Liber Apologeticus Pro Filiis Ludovici Pii Imperatoris Adversus Patrem) manifiesta su preocupación por dicha cuestión, individualizando la contraposición entre la pretendida unidad imperial y la pluralidad de normas vigentes. A fin de superar el contraste jurídico derivado de la diversitas legum, Agobardo propone elegir la lex Francorum como communis lex tanto para los itálicos como para los germanos (Gatto, 2003, p. 147), (Cortese, 2000, p. 139). Sobre la controversial figura de Agobardo vid. Bressolles (1949) y Rubellin (2003).

${ }^{10}$ Concluida la experiencia del Imperio carolingio en el año 843, una nueva tentativa de unificación política se dio con la coronación de Otón I el Grande en el año 962, y la problemática que derivó definida como renovatio o traslatio Imperii de Grecis in Germanos.

${ }^{11}$ Entre los siglos XI y XII se constata una primera sistematización de la producción normativa de matriz eclesiástica, de la cual son un patente ejemplo la Lex romana canonice compta, la Collectio Anselmo dedicata y el Decretum di Burcardo. Además hay una notable actividad normativa con las collectiones de Anselmo de Lucca, del cardenal Deusdedit y de Bonizione de Sutri. Así quedarán sentadas las bases del derecho canónico, cuyos estudios se revelarán con gran fervor especialmente en Italia y Francia (en esta última sobre todo a partir de Ivone di Chartres, a quien se le atribuyen tres collectiones: el Decretum, la Panormia y la Tripartita, surgidas entre fines del siglo XI e inicios del siglo XII).
} 


\section{La polémica entre Martino y Búlgaro en torno a la relación ius/aequitas}

Religión y fe han tenido decisiva importancia durante la Media Aetas. Los predicamentos morales de la Iglesia abrazaban la vida del hombre en todas las dimensiones de su existencia y entraron a formar parte de la doctrina cristiana como imperativos de la conducta humana. Entre tales postulados ético-jurídicos de la doctrina cristiana, orgánicamente proclamada y sostenida por la Iglesia ${ }^{22}$, tenía asignado un rango primordial la aequitas, concebida como el principio fundamental inspirador del orden social ${ }^{13}$.

Es oportuno ahora recordar una polémica surgida en el seno de la Escuela de Bolonia entre dos célebres doctores que sucedieron a su fundador, Irnerio ${ }^{14}$. Se trata de la discusión entre Martino y Búlgaro con respecto al problema de la relación entre equidad y derecho, a la cual ambos juristas deben su fama.

Búlgaro sostuvo una posición que predicaba la observancia rígida del ius scriptum, sin consideración alguna a la gravitación normativa que podía tener el concepto de aequitas. Martino, por el contrario, partiendo de una idea metajurídica de la equidad, afirmaba su predominancia absoluta sobre las reglas positivas y, por ende, reconocía al juez amplísimas facultades para no tener en cuenta tales reglas (si eran contrarias a los principios equitativos) y para crear libremente otras nuevas (Piano- Mortari, 1979, p. 62).

La diferencia de fondo entre Búlgaro y Martino estaba dada por el hecho de que el primero presuponía la equidad como inherente al ius, mientras que el segundo pretendía ejercitar sobre el ius un control equitativo externo y heterónomo. Este control, sin embargo, no debía ser realizado mediante la superposición de un abstracto concepto de equidad extraño al complejo del ius civile, sino por medio de una noción prudentemente inferida de las normas justinianeas (Piano-Mortari, 1979, p. 63) $)^{15}$. La aequitas, así, daba lugar a la formación de un sistema orgánico, animado por un perenne y uniforme

\footnotetext{
${ }^{12}$ En la Antigüedad tardía - enseña Schipani (2005, p. XVIII) (premessa) - las recopilaciones de textos jurídicos de sello cristiano se limitaron a los actos legislativos (cánones, concilios, decretales, etc.), mientras que a partir de la Concordia discordantium canonum, conocida como Drecreto de Graciano (c. 1140), el objetivo de armonizar dichos textos expresa la adopción de un método y actividad doctrinal que se concreta en la construcción de casos de escuela, tanto en los dicta Gratiani, como en las conexiones con textos de derecho romano.

${ }^{13}$ En el Medioevo se entiende que la función del derecho no debía ser simplemente utilitaria, sino tender a la realización de una justicia efectiva y universalmente compartida. En Roma, el término aequitas aludía a la praxis de recurrir a los remedios no escritos propuestos por los juristas y aplicados por el pretor para la solución de las controversias (D. 1,1,7,1 [Papiniano libro II. Definitionum] donde se define el ius praetorium u honorarium por sus funciones supletorias y correctivas: Ius praetorium est, quod praetores introduxerunt adiuvandi vel supplendi vel corrigendi iuris civilis gratia propter utilitatem publicam. Quod et honorarium dicitur ad honorem praetorum sic nominatum [El derecho pretoriano es aquel que los pretores introdujeron para complementar o suplir o corregir (enmendar) el derecho civil, por razones de publica utilidad. También es llamado derecho honorario en virtud del honor que supone el encargo de los pretores].

${ }^{14}$ Con Irnerio se considera que nace la Escuela de Bolonia (o de los glosadores) en la segunda mitad del siglo XI. Las enseñanzas de Irnerio fueron proseguidas por los "cuatro doctores": Búlgaro ("boca de áureas sentencias"), Martino ("del gran conocimiento de las leyes"), Hugo ("que capta el espíritu de las leyes") y Giacomo o lacopo (designado por el propio Irnerio como su sucesor); quienes continuaron el magisterio de su fundador y permitieron que la escuela no quedase reducida a un fugaz episodio ligado exclusivamente a su persona. (Schipani, 2005, p. XVI; Cortese, 2000, p. 261).

${ }^{15}$ Es oportuno recordar el tipo de actividad que realizaban los glosadores. Ellos -enseña Schipani (2005, p. XVI) - trabajaban aclarando los textos de Justiniano con anotaciones al margen ( $g$ lossae) que explicaban el sentido de las palabras utilizadas, mediante una red de llamadas y cotejos con otros usos presentes al interior de la obra de Justiniano. Luego, estaban los casos expuestos, reformulados y examinados (casus), las reglas que podían colegirse de ellos (regulae), e inclusive breves síntesis a modo de epílogo (summae). El texto resultaba así envuelto en una serie de escolios sobre la base de vinculaciones (principalmente con otros puntos del mismo) que orientaban su lectura e interpretación. Del texto asimismo se inferían los dogmata, es decir -en palabras de Azón- los principia et radices super quibus regulariter constituitur fundamentum. La Glossa de Acursio (año 1260) concluye esta época reuniendo y fijando los frutos de un siglo de ingente esfuerzo doctrinario.
} 
carácter racional ${ }^{16}$.

La representación más acotada y eficaz del valor de la aequitas canónica está contenida en el lacónico enunciado nihil aliud est aequitas quam Deus [nada más es la equidad que Dios], cuya autoría habría correspondido al propio Martino, su defensor más férreo ${ }^{17}$. Dicha expresión se inserta en el fragmento que en lo pertinente transcribimos:

...quia iusticiae fons et origo est aequitas, videamus prius quid sis aequitas. Aequitas est rerum convenientia quae in paribus causis paria iura desiderat. Item Deus, qui secundum hoc quod desiderat, aequitas dicitur. Nichil autem est aequitas quam Deus. Si talis aequitas in voluntate hominis est perpetuo, iusticia dicitur. Quae talis voluntas redacta in praceptionem, sive scripta, sive consuetudinaria, ius dicitur.

[Toda vez que la equidad es fuente y origen de la justicia, veamos en primer lugar en qué consiste. La equidad es aquella armonía de hechos que exige un igual tratamiento jurídico para quienes se encuentran en paridad de condiciones. Dios mismo puede ser calificado como equidad. La equidad, en efecto, no es otra cosa que Dios. Esta equidad deviene justicia en el momento en el cual la voluntad humana se apropia de ella. Voluntad que, si se concreta en preceptos (escritos o transmitidos por la tradición oral reiterada por el uso), viene considerada derecho].

El pasaje citado expresa las aspiraciones de la civilización medieval de constituirse bajo un orden unitario. $Y$ esto se realiza mediante un mecanismo donde Dios es la garantía de dicho orden y la equidad la dimensión ordenadora, es decir, el instrumento de la acción divina que desciende gradualmente desde el plano metafísico (representado por la divinidad), pasando por el físico (las cosas, la naturaleza) hasta llegar al nivel de lo humano (la voluntad de los hombres). La equidad se traduce en justicia (es su fuente u origen) y se manifiesta, en definitiva, en un sistema de normas escritas o consuetudinarias (el orden normativo $)^{18}$. En suma, la equidad impregna el universo cósmico e histórico con lo que se llega al extremo de afirmarse que "todo es aequitas" (Dios, la naturaleza, la justicia y el derecho) (Grossi 2004, p. 176, nt. 125) $)^{19}$.

\footnotetext{
${ }^{16}$ Sin embargo, Azón endilgó a Martino el hecho de extraer la noción de equidad arbitrariamente de su propia conciencia, de inventarla ex ingenio suo; de sostener, en fin, una equidad personal in corde retenta, una aequitas ficta, bursalis y capitanea (destinada a prevalecer sobre la ley). Esta imagen de la "equidad gosiana" gozó de predicamento en la historiografía desde el siglo XVIII y fue canonizada por Savigny (Cortese, 2000, p. 262,).

${ }^{17}$ Ha sido Kantorowicz (1938, p. 53) quien atribuyó la expression nihil aliud est aequitas quam Deus al glosador Martino Gosia.

${ }^{18}$ Adviértase que el pensamiento de Martino es coherente con el método de la escuela de los glosadores. Apunta Cortese (2000, p. 262) que preferir la aequitas canónica al rigor secular en ciertos institutos significaba aplicar los mecanismos del utrumque ius, es decir, la integración del derecho civil y del canónico en el sistema unitario del ius commune. En análogo sentido, la labor de interpretatio actuada por los juristas medievales ha sido concebida como un "...momento di sutura tra autorità e ragione, e tra logica ed aequitas" (Gambaro \& Sacco, 2008, p. 188).

${ }^{19}$ La noción medieval de aequitas no es un mero concepto ético, sino la misma linfa del ordenamiento que impregna la ley, la obra de los intérpretes y la resolución de los juicios, y que coincide con el orden o estructura de la realidad tal como ha sido querida y creada por Dios: aequitas in rebus ipsis percipitur [la equidad se capta, se deduce de la naturaleza misma de las cosas] (Cortese, 1964, p. 30, nt. 71).
} 


\section{El orden unitario medieval y la aequitas cristiana}

Es momento de precisar el alcance de la aequitas según el parecer de los juristas medievales seguidores de la dirección doctrinaria inaugurada por Martino. Según esta corriente, amén de la aequitas positiva (expresamente acogida en el ordenamiento por el legislador [aequitasscripta o constituta]), era imperativa (cogente) aquella que - aunque no estuviere codificada (aequitasrudis) - al menos podía ser inferida por analogía de otras leges (Cortese, 1964, p. 32, nt. 12-13).

Empero, fuerza recordar que el procedimiento interpretativo analógico se encontraba previsto de manera explícita por Justiniano y, por lo tanto, era un principio interno del derecho vigente. Por consiguiente, la equidad que podía prevalecer sobre el ius strictum en todo caso podía ser considerada en sentido lato una aequitas positiva; pues, aunque fuera non scripta, nunca se hallaba determinada sobre la base de principios creados libremente por el intérprete, sino extraídos de las leyes por medio de regulares procedimientos hermenéuticos previstos en el ordenamiento normativo (Piano-Mortari, 1979, p. 65) ${ }^{20}$.

Con tales alcances la aequitas tenía asignado un valor central en el pensamiento medieval, hasta el punto de que se ha afirmado que la idea de un ius naturale impreso por Dios en las conciencias de los hombres semper aequum ac bonum y por tanto inmutable e inviolable, debía representar el punto más firme que - frente al derrumbe de la civilización antigua - podía ofrecer el canon eterno de lo justo y de lo injusto. Encuadrado este concepto en el sistema normativo concebido por la Iglesia, la idea cristiana se acentúa y perdura como dominante, mientras que paralelamente las tendencias helénicas irán destiñéndose y perdiendo fuerza (Calasso, 1954, p. 333) $)^{21}$.

Tales exigencias ideales que provenían de un estado de cosas concreto, se reflejaron claramente en la nueva aequitas que exalta la Iglesia22. La aequitas para la Iglesia no importa solamente - como a menudo se piensaun sentimiento de bondad, moderación e indulgencia que atempera el rigor de la ley escrita, sino además un principio de orden gobernado por una ratio (aequitatis ratione) (Calasso, 1954, p. 334).

Es muy importante este concepto de "orden" (ordo) que entraña la aequitas cristiana. Evidentemente la aequitas así concebida desempeñaba un rol directivo innegable, por cuanto servía para asegurar la unidad del sistema y justificaba el control ejercido por la Iglesia sobre el mismo. Con una expresión muy gráfica se ha dicho que la aequitas hacía las veces de "anillo de conjunción" entre el derecho natural y el derecho civil en el marco de un sistema normativo unitario (Cortese, 2000, p. 271).

\footnotetext{
${ }^{20}$ El autor arriba a otra conclusión: presuponiendo que dentro de tales límites deben ser comprendidas las posiciones de Martino, no puede sorprender "...la insistenza, in altreparole, sulla certeza dell'aequitas munita di adminicula, riferibile chiaramente a concetti predisposti dal diritto positivo" (p. 66).

${ }^{21}$ El autor recupera la idea de aequitas como uno de los cimientos sobre los que se ha edificado el sistema de derecho común en los siglos XII-XV. El período áureo de esta construcción arranca con el surgir de la nueva figura del jurista integral (no solo civilista o canonista), experto quo ad utrumque ius (Calasso, 1966, p. 68).

22 En el pensamiento medieval la equidad se presentaba también en la tradición retórica bajo la especie de un par de definiciones. La primera proviene de Cicerón (Topica, 4,23), quien la define como un principio de igualdad o proporcionalidad (aequitas = aequalitas) que exige identidad de tratamiento jurídico en presencia de idénticas fattispecie concretas (in paribuscausis paria iura desiderat). La segunda, que aparece en los antiguos tratados medievales y en las célebres Questiones de iuris subtilitatibus (obra jurídica de paternidad ignota, pero atribuida a Irnerio en la edición de Fitting, H. (1894). Questiones de iuris subtilitatibus des Irnerius (Reimpresión de 1977). Berlín: Walter de Gruyter \& Co., p. 54 [I, 3]), describe la aequitas - en sentido particular - como la correspondencia del acto jurídico con su causa; en lenguaje actual se podría decir, con el esquema típico de la fattispecie (v.gr., si el vendedor entrega la cosa, la equidad exige que el comprador pague el precio, y viceversa). Esta "causa natural" no es una creación de la ley sino reside en los hechos mismos, en la "naturaleza" de las relaciones, es expresión en suma del derecho natural. Los doctores medievales designaban a esta especie, aequitas rudis ("en bruto"), y era tarea del legislador darle forma, dotarla de autoridad y comprenderla en el acto volitivo (la ley). Así, la aequitas rudis se convertía en aequitas constituta y transformaba el derecho natural en derecho civil (Topica 2,9). Para todo Cortese (2000, p. 270).
} 
En suma, se trataba de un elemento positivo y constructivo, sobre el cual la Iglesia enseñaba que debía fundarse el gobierno de los pueblos y en cuyo nombre se condenaban las injusticias cometidas por los hombres. En otras palabras, aequitas era el principio en virtud del cual podía ser conservada la paz y la concordia; evocaba una justicia que respondía a los preceptos divinos (proclamada solemnemente por un sínodo de la edad carolingia como aequitas et iustitia populi christiani). Así, con frecuencia se aprecia en documentos eclesiásticos (e inclusive seculares) el empleo de binomios como: iustitia et aequitas, veritas et aequitas, aequitas et ratio (Calasso, 1954, p. 334).
Ya en los albores del cristianismo de época visigoda, luego del derrumbe del Imperio romano de Occidente, Isidoro de Sevilla (c. 556-630 d.C.) ${ }^{24}$ definía como aequus aquello que est secundum naturam iustus dictus (Originum sive etymologiarum libri viginti, $\mathrm{X}, 7$ ) (Palazzo, 2002, p. 41). Integrando esta definición con la de lex y de consuetudo, aparece esencialmente formulado el concepto de aequitas prohijado por la Iglesia, donde secundum naturam equivale a secundum Deum. La aequitas, en suma, es la adecuación final de cada norma humana al precepto de Dios, por la actuación de la iustitia sobre la Tierra (Calasso, 1954, p. 336) ${ }^{25}$.

\section{Carácter emblemático del iudicium aequitatis}

La concepción medieval, fundada en la necesidad de que el derecho positivo no estuviera en contradicción con los valores éticos y religiosos del cristianismo, determinó que el ius quedara subordinado a la aequitas. En los capitularia carolingios encontramos ya afirmada la exigencia de racionalidad (rationabilitas) a la cual debía someterse el legislador, quien debía inspirarse tanto en la justicia como en la razón para dar fundamento a las leyes ${ }^{26}$.
Este efecto omnicomprensivo de la aequitas cristiana ya viene icásticamente representado por un instituto cuyos orígenes se remontan a la alta Edad Media: el iudicium aequitatis ${ }^{27}$. En el Imperio carolingio esta modalidad de juzgamiento se desarrollaba en el Palatium regis: el tribunal que debía pronunciarse de manera definitiva en las litis que habían sido resueltas anteriormente por otros jueces. Las causas sometidas

\footnotetext{
${ }^{23}$ Así, la iustitia coincide con la divina voluntas: Divinam voluntatem vocamus iustitiam [a la Divina voluntad llamamos justicia]; y de la iustitia la aequitas es la fons et origo [fuente y origen], conforme se lee en una glosa de la época (Fedele, 1966, p. 148).

${ }^{24}$ En época visigoda fue notable la influencia de las Etymologiae. En España sirvieron de base para la enseñanza y en el resto de Europa constituyeron un documento clave para conocer la cultura latina. Sin embargo, comparando los extractos que evidencian su fondo romanista con las colecciones justinianeas o con obras anteriores de la jurisprudencia romana, se aprecia un retroceso en términos cualitativos. Con todo "...gracias a ese pequeño compendio se conservó en gran parte el conocimiento del Derecho romano en la primera parte de la Edad Media" (Riaza, 1998, p. 32; Riaza, 1932).

${ }^{25}$ Y coherentemente con ello, la fides era concebida por Isidoro de Sevilla como lealtad a la palabra dada (fit quod dicitur), siguiendo las huellas de Cicerón (De officiis1,7,23; De re publica, 4,7,21; Ad familiae 16,10,2) y luego de San Agustín (Sermones 49,2: fides appellata est ab eo quia fit quod dicitur [se ha llamado fides por el hecho de que se hace lo que se dice]). En este sentido, en un fragmento de las Etymologiae $(8,2,4)$ se afirma que: "Nomen fidei inde est dictum, si omino fiat quod dictum est au tpromissum, et inde fides vocata ab eo quod fit illud quod inter Deum et hominem hinc et foedus [Se ha dado el nombre de fides cuando se ha llevado a cabo totalmente lo que se ha dicho o prometido y por eso se ha llamado fides, por el hecho de que se hace aquello que se acordó entre uno y otro, por ejemplo entre Dios y el hombre: de aquí también foedus]".

${ }^{26}$ A este respecto Piano Mortari (1979, p. 27) recuerda que el requisito de la rationabilitas, es decir, de la conformidad de la costumbre a la razón (entendida como correspondencia con los principios de la verdad emanados de leyes divinas y naturales), reconocía ciertos rastros en algunos pasajes de las fuentes jurídicas romanas. Empero, la Iglesia al introducir el principio de la adprobatio hizo necesario que la autoridad eclesiástica verificara en toda norma consuetudinaria su concordancia intrínseca con la iustitia, la aequitas y la rationabilitas, como conditio sine qua non para que la misma pudiere adquirir el valor de una regla jurídica. Con ello se sentaron las bases para una "... teoria de la consuetudine tutta diversa da quella ereditata dal diritto romano e dai diritti germanici".

${ }^{27}$ Para ampliar, vid. el completo estudio de E. Kaufmann (1959).
} 
al iudicium aequitatis debían decidirse con arreglo a la equidad, según los criterios de justicia y racionalidad derivados de los preceptos cristianos y sin atender al derecho vigente cuando las normas positivas estuvieran en discordancia con dichos preceptos. De tal guisa, el Palatium regis, presidido por el emperador y compuesto tanto por laicos como por eclesiásticos, se erigía como el máximo órgano jurisdiccional de un imperio que se proclamaba sostenedor y defensor de la Iglesia.

Es sumamente relevante la idea superior que anima esta institución: ut et coram Deo propter iustitiam et coram hominibus propter legum observationem cunctis placeret [frente a Dios debe ejecutarse la justicia y frente a los hombres corresponde la observancia de todas las leyes que a ellos convienen]. El iudicium aequitatis se lleva a cabo, por tanto, no solamente basado en las leges (derecho positivo), sino además con fundamento en la iustitia que emana inmediatamente de los preceptos divinos ${ }^{28}$.

Así, toda vez que la controversia que se decide definitivamente en la instancia del iudicium aequitatis hubiese sido previamente juzgada en base a una norma no contenida en las leges mundanae [leyes temporales] o bien con una crueldad que no se compadecía con la christianitatis rectitudo vel sancta auctoritas [cristiana rectitud y santa autoridad], entonces debía intervenir la moderatio regis [moderación regia] sustentada en el consejo de hombres qui utramque legem nossent et Dei magis quam humanarum legum statuta metuerent [que tengan igualmente versación en uno y otro derecho y teman más a la ley divina que a las leyes humanas] y debía reexaminarse la causa, procurando conservar en la medida de lo posible utramque legem [ambas leyes, tanto la ley divina como la ley civil]; pero si esto no era factible, el sumo criterio debía ser: lex saeculi merito comprimeretur, iustitia Dei conservatur [la ley secular debía ceder y la justicia divina ser preservada] ${ }^{29}$.

Sobre tales premisas, el Supremo Tribunal carolingio entendía que rendía la más alta justicia a los pueblos armonizando la iustitia Dei. Y en su concepción, la aequitas era equivalente a esta armonía divina (Calasso, 1954, p. 336).

\footnotetext{
${ }^{28}$ Esta forma de revisión de los procesos se realizaba en todas las contentiones alibi ortae [contiendas originadas en otra instancia] para decidirlas definitivamente y reconducir ad aequitatis tramitem aquellas causas perverse iudicatae [incorrectamente juzgadas] (PianoMortari, 1979, p. 28).

${ }^{29}$ Ver: Hincmaro de Reims (1884, pp. 54-56), IAdmonitio hincmari. Remorum archiepiscopi. Ad episcopos et ad regem karolomannum per Capitula, en el capítulo § XXI: “Le comte du palais, parmi ses attributions presque innombrables n'en vait pas de plus importante que de terminer, selon la justice et la raison, tous les procès légaux qui, nés ailleurs, étaient apportés au palais pour y recevoir une solution conforme à l'équité, et aussi de réformer les jugements mal prononcés; de manière à plaire à tous: à Dieu, par sa justice, aux hommes, par son respect des lois. Un cas se présentait-il, que les lois séculières n'eussent pas prévu dans leurs décisions ou sur lequel la coutume païenne eût statué plus cruellement que ne le comportent la justice chrétienne et la sainte autorité de l'Eglise, on en remettait l'examen au roi, afin qu'avec l'assistance de personnes également versées dans l'un et l'autre droit et craignant la loi de Dieu plus que les lois humaines, il en décidât de façon à concilier ces législations toutes les fois qu'elles pouvaient l'être; si cela était impossible, la loi du siècle devait, comme il convient, céder devant la justice de Dieu".
} 


\section{Simbiosis de la bona fides con la aequitas}

En el contexto descrito en los apartados anteriores la bona fides ingresa en un proceso en virtud del cual comienza a diluirse el contenido fraguado durante el derecho romano clásico por obra de los juristas en la determinación de aplicaciones operativas concretas. La aequitas cristiana, a su turno, identificada con la ausencia de pecado y el correlativo valor sagrado que adquiere el respeto por la palabra dada - en una suerte de proceso osmótico - termina absorbiendo a la buena fe ${ }^{30}$.

La aequitas ${ }^{31}$, con un neto fundamento teológico, resulta así enriquecida y con una relevante gravitación en la evolución posterior del pensamiento jurídico. En estos términos, la aequitas se contrapone al ius strictum ${ }^{32}$. E rigor iuris de este último conlleva un exceso de severidad que puede ser útil en ciertos casos ("quando ad terrorem proceditur excedendo in aponendo poenae modum"). La aequitas, en contraposición al ius strictum, es configurada como iustitia dulcore misericordiae temperata ${ }^{33}$.

Esta es, en definitiva, la intelección canónica de la aequitas, según la cual podía conducir a una desaplicación del derecho vigente toda vez que la regla jurídica contrastare con la misericordia ${ }^{34}$. En este sentido, para algunos autores la aequitas ha dado vida a una suerte de ordenamiento paralelo con una función correctiva semejante a la que tenía el ius honorarium en la experiencia romana ${ }^{35}$.

\footnotetext{
${ }^{30}$ Los doctores medievales identifican la aequitas con la bona fides. Así, por ejemplo, Benincasius, Ad tit. De actionibusinterpr., 198 n. 109 y 112: "Bona fides nihil aliud est quam aequitas iuris gentium" y "... bonae fidei dicitur ratione aequitatis".

${ }^{31}$ Gordley (2000, p. 108): "Baldus identified good faith with equity and with conscience. But he gave special attention to one particular requirement of equity and good faith: the requirement that no one should be enriched at another's expense. This principle looks like the principle of equality which, according to Aristotle and Thomas Aquinas, is the foundation of commutative justice. Baldus called it 'the rule of rules in the life of conscience'".

${ }^{32}$ Roesenerus, Thesaurus, 122 par. 6; Calvinus, Lexicon, 119: "Bona fides alias aequum et bonum significat".

${ }^{33}$ La expresión pertenece a Benincasius, Ad Tit. De actionibus interpr., 198 n. 120 y 123.

${ }^{34}$ Para ampliar sobre el punto vid. Caron (1971).

${ }^{35}$ Así R. Fiori (2007, p. 33) traza una comparación con otras experiencias que en la historia fundaron sistemas separados del derecho civil; por ejemplo, la equity inglesa, concebida en sus orígenes como un "derecho de gracia regio" para atemperar la rigidez del common law, y administrada hasta el siglo XVI por los cancilleres eclesiásticos.
} 


\section{Los predicados de la moral cristiana y el valor espiritual de la buena fe}

El hecho de que con el objeto de captar la esencia de la bona fides los juristas medievales hayan recurrido a una serie heterogénea de palabras (constantia, veritas, iustitia, natura, conscientia), refleja la extraordinaria complejidad del terreno en el cual pervivió la bona fides en edad intermedia. Lo cierto es que desde la comprensión del derecho canónico, el instituto jurídico de la buena fe quedará indisolublemente ligado a la ausencia de pecado y se traducirá en un estado de conciencia del individuo ${ }^{36}$.

La Iglesia atribuía valor moral a la promesa o al consentimiento, porque la mentira era considerada un pecado (catalogada por los teólogos como "pecado de la lengua") ${ }^{37}$. La idea del pecado (o, mejor dicho, del periculum que su comisión conlleva) representa el nuevo principio informador del concepto canónico de la bona fides (Albisetti, 1980, p. 172). La buena fe se inscribe en un marco teológico-moral en cabal sintonía con los principios fundamentales que rigen el ordenamiento jurídico de la Iglesia, entre los cuales se encuentra la ratio vitandi peccati o bien el riesgo que corre la salus animae. Así, se acrecentó el factor espiritual de la buena fe que adquirió una fuerte carga de eticidad y se situó en una dimensión axiológica compatible con la moral cristiana.

El cristianismo habría influido, a través del derecho canónico, en esta suerte de espiritualización del contrato, consistente en la valorización preeminente o exclusiva de la voluntad subjetiva de los contratantes, la cual tendría fuerza obligatoria por sí misma, pues por motivos éticoreligiosos era menester que el hombre respetase la palabra empeñada ${ }^{38}$.

\section{Persistencia de cierta valencia técnica de la bona fides en el pensamiento canónico medieval}

En todo caso, la explicitada dimensión teológicomoral no agotaba in totum la noción de la buena fe en el derecho canónico clásico. Si bien es verdad que los canonistas tendieron a valorizar el aspecto fiduciario de dicha noción identificándola con la ausencia de pecado, no renunciaron a utilizar - aunque más no sea de manera instrumental- en sus construcciones teóricas, el concepto estrictamente jurídico de la buena fe (ScavoLombardo, 1995).

En efecto, más allá del relativo desvanecimiento experimentado por la buena fe en el derecho canónico, la misma fue objeto de tratamiento en dos sectores jurídicos bien delimitados: a) en orden a la protección

\footnotetext{
${ }^{36}$ En el pensamiento filosófico medieval la dicotomía peccatum-officium fue enormemente fecunda a partir de las reflexiones de San Agustín y Santo Tomás de Aquino. Se logra captar el significado de ambos términos en un conocido texto de Cicerón (De Officiis 3,35,95) donde se trata el caso del depósito de una espada por alguien que la reclama después de haber sido declarado demente (insanus). Habida cuenta del peligro que un arma puede significar en manos de alguien que tiene sus facultades mentales alteradas, devolvérsela sería un peccatum (una acción cuanto menos imprudente), mientras que negarse a la restitución es un deber moral (officium) que ha de observarse (Giménez-Candela, 2006, p. 133).

${ }^{37}$ En las fuentes jurídicas romanas ya se advierte el sentido de peccare como falta cometida por impericia o imprudencia (D. 19,2,9,5; D. 50,13,6); pero también como delitoo incumplimiento de las leyes (D. 44,7,52 pr.; D. 44,7,52,8; D. 47,10,18 pr.; D. 50,16,131,1 y D. 50,16,244), en cuyo caso peccator equivale a delinquens (J. 4,18,4,8). En los textos literarios peccatum aparece también usado en el sentido de "falta, acción culpable o crimen", "ofensa moral" o "error" en textos de Cicerón (Ac. 1,37; Fin. 3,32; Tusc. 3,47; Fin. 4,40; de Orat. 1,124), Varrón (L. 9,10; 10,60), Tito Livio $(23,18,13 ; 42,60,5)$ y Ovidio (Fast. 2,522).

${ }^{38}$ La particular óptica del derecho canónico se funda en la preocupación por tutelar la salus animae y por ello se conjuraba el mendacium (Fedele, 1937, p. 5).
} 
posesoria, a la hora de calificar la prescripción adquisitiva o usucapión ${ }^{39}$; y b) con respecto a la legitimación y eficacia de los nuda pacta [pactos desprovistos de forma] ${ }^{40}$.

En ambos campos la buena fe conservó una definida precisión técnica y los juristas de la edad intermedia apoyaron sus construcciones en dos textos de época romana. Uno de ellos perteneciente al jurista Trifonino, del cual era posible extraer el principio por el cual en todas las relaciones negociales la bona fides importaba la observancia de un deber de lealtad en el comportamiento, contrapuesto al fraus y al dolus ${ }^{41}$. El otro texto corresponde a Modestino, donde a propósito de la emptio, la bona fides es delineada según una doble perspectiva que presupone situaciones psicológicas diversas: ignorancia del comprador que la cosa fuese ajena, o convicción del comprador de que quien enajenó la cosa tuviese el ius vendendit2.
También puede mencionarse como una contribución relevante del derecho canónico, siempre con fundamento en la noción subjetiva de buena fe, la relativa a los efectos del matrimonio putativo en miras a la situación jurídica del cónyuge inocente, es decir, de aquel que ignora la existencia de un impedimento para contraer válidamente matrimonio ${ }^{43}$.

En suma, las elaboraciones formuladas en torno al concepto de buena fe en el derecho canónico ponen de realce la armónica simbiosis entre lo moral y lo jurídico que constituye la impronta más característica del mundo medieval, donde el civis no es separable del fidelis. Un mundo en el que la experiencia jurídica es al mismo tiempo una experiencia ética y el derecho constituye una derivación de precisos presupuestos religiosos (Grossi, 1966, p. 113).

\footnotetext{
${ }^{39}$ Confrontar sobre el punto la primera monografía aparecida en escena de F. Ruffini (1892). En materia de prescripción adquisitiva la buena fe subjetiva se torna un estado de conciencia individual, requiriendo no solo la mera ignorancia (como en el derecho romano), sino además la convicción íntima y subjetiva de la ausencia de pecado, de estar actuando correctamente y no lesionar una regla jurídica o un derecho ajeno. De esta manera el derecho canónico (en virtud de su fundamento moral) propugna un principio contrario al que por razones de certeza y seguridad se había acuñado en el derecho romano: mala fides superveniens nocet. Se mantiene así la exigencia de la continuidad de la buena fe durante todo el tiempo necesario para la usucapión. Ver V. Kluger (2004, p. 96). En este mismo sentido se enrola el Código de Derecho Canónico promulgado por la Autoridad del Sumo Pontífice Juan Pablo II (Roma, 25 de enero de 1983), cuando en su canon 198 preceptúa que: "Nulla valet praescriptio, nisi bona fide nitatur, non solum initio, sed toto decursu temporis ad praescriptionem requisiti, salvo praescriptio can. 1362" [Ninguna prescripción tiene validez si no se funda en la buena fe, no sólo al comienzo sino durante todo el decurso de tiempo requerido para la misma, salvo lo establecido en el canon 1362].

${ }^{40}$ Los canonistas postulan la validez de los nuda pacta, es decir, con absoluta independencia de la observancia de formas (escrituración, entrega, palmada), posición que ya se venía perfilando en el derecho bizantino con base en la fides y el respeto a la palabra dada. El tratamiento conferido por el ius canonicii a la buena fe provoca una subversión del viejo adagio formulado por Ulpiano: "ex nudo pacto actio non nascitur o non parit” (D. 2,14,7,4). Por ello se ha señalado que “...en el derecho romano de todas las épocas, el consensualismo es un principio excepcional" (Guzmán-Brito, 1966, p. 120).

${ }^{41}$ D. 16,3,31,1 Trifonino libro IX. Disputationum: "Ocurre aquí también otra consideración, ¿debemos estimar la buena fe solamente en aquellos entre quienes se contrató, sin atender a ninguna cosa extrínseca, o también con respecto a las demás personas a quienes pertenece lo que se trata? Por ejemplo, un ladrón depositó en poder de Seyo, que ignoraba la malicia del que los depositaba, los despojos que me quitó; ¿deberá acaso Seyo restituirlos al ladrón, o a mí? Si atendemos al que por si da y recibe, esta es la buena fe, que reciba la cosa depositada el que la dio; si a la equidad de todo el caso, que se consuma en virtud de todas las personas que intervienen en este negocio, se me han de devolver a mí, a quien se quitaron por acto muy criminal; y apruebo que esta sea la justicia, la cual da a cada uno lo suyo, de suerte que no sea segregado de la reclamación más justa de alguna persona. Pero si yo no compareciera para reclamarlos, han de ser no obstante restituidos al que los depositó, aunque los depositó mal adquiridos; lo que escribe también Marcelo respecto al poseedor de mala fe y al ratero. Mas si ignorando el ladrón al hijo o al esclavo de quien hubiese hurtado una cosa, la depositó en poder del padre o del señor de aquel, que lo ignoraba, ni aun por derecho de genes existirá el depósito; cuya eficacia es esta, que a otro, no al dueño, se dé para guardarla como ajena la cosa propia de él mismo. Y si una cosa mía, que me hurtó ignorándolo yo, la hubiere un ratero depositado en mí, ignorando también ahora su delito, con razón se dirá, que no se verifica depósito, porque no es de buena fe que sea compelido el dueño a restituir su propia cosa a un ladrón; pero aun si también en este caso hubiera sido entregada como por causa de depósito por el dueño que lo ignorase, competerá sin embargo la condición de lo dado no habiendo sido debido" [Nota del autor: Se transcribe solo la versión en español del fragmento debido a su extensión].

${ }^{42}$ D. 50,16,109 Modestinus libro V. Pandectarum. "Bonae fidei emptor" esse videtur, qui ignoravit eam rem alienam esse, aut putavit eum qui vendidit ius vendendi habere, puta procuratorem aut tutorem esse [Se considera que es comprador "de buena fe" el que ignoró que la cosa era ajena, o creyó que el que la vendió tenía derecho para venderla, por ejemplo, que era procurador o tutor].

${ }^{43}$ Así en el citado Código de Derecho Canónico (1983), el canon 1061 § 3 dispone que: "El matrimonio inválido se llama putativo, si fue celebrado de buena fe al menos por uno de los contrayentes, hasta que ambos adquieran conocimiento cierto de la nulidad". Respecto de este canon se ha dicho que reclama "...in modo palese la nota impostazione canonistica secondo la quale la bona fidesappare elemento essenziale e qualificante del cosiddetto matrimonio putativo" (Albisetti, 1980, p. 1). Para ahondar en la materia se puede ver M. López Alarcón (1998).
} 


\section{Colofón}

La aequitas canónica, en razón de la compleja realidad medieval en la que se inscribe y de la que intenta dar cuenta, es un concepto altamente polivalente. En un intento de síntesis es dable individualizar en el término una significación genérica (A) y dos acepciones específicas (B, i-ii).

A) Por una parte, la aequitas hace referencia a la noción acuñada y utilizada por los glosadores (canonistascivilistas) como una de las piedras angulares del sistema de derecho común. A la luz de las concepciones predicadas por la Iglesia, en la tarea que la misma asume de reducir a unidad (reductio ad unum) la íntegra realidad de entonces, se afirma que "todo es aequitas". De aquí se colige que la aequitas no solo fue considerada un canon especulativo, sino un principio de origen divino con pretensiones de ordenar la realidad en su conjunto. Esto suponía "la adecuación final de cada norma humana al precepto de Dios" y como consecuencia "podía ser conservada la paz y la concordia sobre la tierra".

B) Amén de esta acepción general, la aequitas canónica encierra en sí dos sentidos específicos que con el transcurrir del tiempo terminaron secularizándose (impregnando nuestras concepciones actuales del término). Veamos:

i) La aequitas declinada como aequalitas (proporcionalidad). En este sentido la aequitas exige igualdad de tratamiento en presencia de idénticas condiciones (in paribus causis paria iura desiderat) o simplemente puede traducirse como proporcionalidad entre lo dado y lo recibido. Esta noción tiene raíces en el pensamiento romano, estando presente en la retórica de Cicerón (Topica 4,23) y con antecedentes más estrictamente jurídicos en las ideas de Aristón sobre el synállagma (D. 2,14,7,2). Siglos más tarde, en el ámbito del discurso iusnaturalista, será retomada por Pufendorf para explicar la categoría de los contratos onerosos. En las codificaciones civiles modernas, finalmente, vendrá empleada para justificar la revisión del contrato cuando se verifica una alteración originaria o sobrevenida del equilibrio de las prestaciones (en los casos de lesión e imprevisión, respectivamente).

ii) También con valor semántico preciso (que aparece en los antiguos tratados medievales y en las célebres Questiones de iuris subtilitatibus atribuidas a Irnerio) se describe la aequitas como la correspondencia del acto jurídico con su causa, o sea con el esquema típico de la fattispecie (si el vendedor entrega la cosa, la equidad exige que el comprador pague el precio, y viceversa). Esta "causa natural" no es una creación artificial de la ley sino reside en los hechos mismos (in re ipsa), en la naturaleza de las relaciones. Los doctores medievales la designaban aequitas rudis y era tarea del legislador darle forma, dotarla de autoridad legal; así, se convertía en aequitas constituta y transformaba el derecho natural en derecho civil (Cicerón, Topica 2,9). 


\section{Referencias}

Albisetti, A. (1980). Contributo allo studio del matrimonio putativo in diritto canonico: violenza e buona fede. Milán: Giuffrè.

Astuti, A. (1958). Capitolari. En Novissimo Digesto Italiano, 2 (pp.918-925). Turín: UTET.

Astuti, G. (1975). Influssi romanistici nelle fonti del diritto longobardo. En. La cultura antica nell'occidente latino dal VII all'XI secolo (pp. 653-703). Spoleto: Fondazione Centro italiano di studi sull'alto Medioevo (CISAM).

Brandileone, F. (1929). L'Italia bizantina e la sua importanza nella storia del diritto italiano. En Studi in onore di Pietro Bonfante nel XL anno d'insegnamento, 2. Pavía: Tipografia Fratelli Fusi.

Bressolles, A. (1949). Saint Agobard, évêque de Lyon (769-840). En Doctrine et action politique d'Agobard, 1. Paris: J. Vrin.

Calasso, F. (1954). Medio Evo del Diritto, 1. Milán: Giuffrè.

Calasso, F. (1966). Equità: Premessa storica. En Enciclopedia del diritto, 15. Milán: Giuffrè.

Caron, P. G. (1971). Aequitas romana, misericordia patrística ed epieicheia aristotélica nella dottrina dell' aequitas canonica: dalle origini al Rinascimento. Milán: Giuffrè.

Cavanna, A. (1968). Nuovi problemi intorno all'editto di Rotari. Studia et documenta historiae et iuris, (34), 269-361.

Roma: Pontificia Universitas Lateranensis.

Cortese, E. (1964). La norma giuridica: Spunti teorici nel diritto comune classico, 2. Milán: Giuffrè.

Cortese, E. (2000). Le grande linee della storia giuridica medievale. Roma: II Cigno Galileo Galilei.

Cortese, E. (2013). lus commune. En Diccionario General de Derecho Canónico, 4 (pp. 823-829). Navarra: Thomson Reuters-Aranzadi.

Di Simone, M. R. (2007). Istituzioni e fonti normative in Italia dall'antico regime al fascismo. Turín: Giappichelli.

Fedele, P. (1937). Considerazioni sulla natura dei patti nudi nel diritto canonico. En Annali della Facoltà di Lettere e

Filosofia della Università di Macerata, 11. Nápoles: Libreria Scientifica Editrice.

Fedele, P. (1966). Equità canonica. En Enciclopedia del diritto, 15. Milán: Giuffrè.

Fiori, R. (2007). Storicità del diritto e problemi di metodo: L'esempio della buona fede oggettiva. En L. Garofalo (Dir.).

Scopi e metodi della storia del diritto e formazione del giurista europeo (Incontro di studio, Padova 25-26 novembre 2005). Nápoles: Jovene.

Gambaro, A. \& Sacco, R. (2008). Sistemi Giuridici Comparati. Turín: UTET.

Ganshof, F. L. (1958). Recherches sur les capitulaires. París: Sirey.

Gatto, L. (2003). II Medioevo: Giorno per giorno. Roma: Newton \& Compton.

Giménez Candela, T. (2006). La modificación de las condiciones del contrato: la cláusula "rebus sic stantibus". En

Roma e America: Diritto Romano Comune, 22. Módena: Mucchi.

Gordley, J. (2000). Good Faith in contract law in the medieval ius commune. En R. Zimmermann y S. Whittaker

(Coords.). Good Faith in European Contract Law. Cambridge: Cambridge University Press.

Grossi, P. (1966). Somme penitenziali, diritto canonico, diritto comune. En Annali della Facoltà giuridica dell'Università di Macerata, 1. Nápoles: Libreria Scientifica Editrice.

Grossi, P. (2004). L'ordine giuridico medievale. Bari: Laterza.

Guzmán Brito, A. (1966). Derecho Privado Romano, 2. Santiago: Editorial Jurídica de Chile.

Hincmaro de Reims (1884). De ordine palatii epistola (título dado por Sirmond, editor del siglo VII de la obra). M. Prou

(Trad.). Paris: Edition de la Bibliothèque de l'École des hautes études. Sciences philologiques et historiques.

Kantorowicz, G. (1938). Studies in the glossators of the roman law: Newly discovered writings of the twelfth century. Cambridge: Cambridge University Press. 


\section{Apuntes sobre la aequitas en la tradición canónica medieval}

Kaufmann, E. (1959). Aequitatisiudicium.Königsgericht und Billigkeit in der Rechtsordnung des frühen Mittelalters. Frankfurt: Vittorio Klostermann.

Kluger, V. (2004). Una mirada hacia atrás de Roma a la codificación: El recorrido histórico de la buena fe. En M. M. Córdoba (Dir.). Tratado de la Buena Fe en el Derecho, 1. Buenos Aires: La Ley.

López Alarcón, M. (1998). Algunas consideraciones sobre el matrimonio putativo. Revista Anales de Derecho, (16), 127-138.

G. F. Margadant, (1986). La segunda vida del Derecho Romano. México: Porrúa.

Palazzo, A. (2002). Interessi permanenti nel diritto privato ed ética antica e moderna. En A. Palazzo \& I. Ferranti (Coords.). Etica nel diritto privato, 1. Padua: CEDAM.

Piano Mortari, V. (1979). Aspetti del pensiero giuridico medievale. Nápoles: Liguori.

Riaza, R. (1932). Las Etimologías de San Isidoro. Versión castellana. Varios fragmentos de interés jurídico. Revista de Ciencias jurídicas y sociales, 15, 383-412.

Riaza, R. (1998). Historia de la literatura jurídica española. Interpretatio: Revista de historia del derecho, 5, $19-222$.

Rubellin, M. (2003). Église et société chrétienne d'Agobard à Valdès. Lyon : Presses Universitaires de Lyon.

Ruffini, F. (1892). La buona fede in materia di prescrizione: Storia della teoría canonistica. Turín: Bocca.

Scavo Lombardo, L. (1995). La buona fede nel diritto canonico. Bolonia: II Mulino.

Schipani, S. (2005). Iustiniani Augusti Digesta seu Pandectae. Milán: Giuffrè. Tosi, M. (1982). L’Edictus Rothari nei manoscritti bobiensi. En Archivum Bobiense. Rivista degli Archivi Storici Bobiensi, 4, 11-72. 